\title{
Polymorphisms in Four Genes (KCNQ1 rs151290, KLF14 rs972283, GCKR rs780094 and MTNR1B rs10830963) and Their Correlation with Type 2 Diabetes Mellitus in Han Chinese in Henan Province, China
}

Kaiping Gao ${ }^{1, *, \dagger}$, Jinjin Wang ${ }^{2,+}$, Linlin $\mathrm{Li}^{3}$, Yujia Zhai ${ }^{3}$, Yongcheng Ren ${ }^{3}$, Haifei You ${ }^{3}$, Bingyuan Wang ${ }^{3}$, Xuli Wu ${ }^{1}$, Jianna $\mathrm{Li}^{1}$, Zichen Liu ${ }^{1}$, Xiong Li ${ }^{1}$, Yaxin Huang ${ }^{1}$, Xin-Ping Luo ${ }^{1}$, Dongsheng $\mathrm{Hu}^{1}{ }$, Kinji Ohno ${ }^{4}$ and Chongjian Wang ${ }^{3, *}$

1 Department of Preventive Medicine, School of Medicine, Shenzhen University, Shenzhen 518060, China; wxl@szu.edu.cn (X.W.); lijianna@szu.edu.cn (J.L.); daisysg@szu.edu.cn (Z.L.); lixiong1@email.szu.edu.cn (X.L.); hyx413459261@sina.com (Y.H.); lxp2005@szu.edu.cn (X.-P.L.); hud@szu.edu.cn (D.H.)

2 Department of Traditional Chinese Medicine Prevention, Preventive Medicine Research Evaluation Center, Henan University of Traditional Chinese Medicine, Zhengzhou 450001, China; wangjinjin510@163.com

3 Department of Epidemiology, College of Public Health, Zhengzhou University, Zhengzhou 450001, China; lilinlin@zzu.edu.cn (L.L.); zhaiyujiamodi@163.com (Y.Z.); ryc12@sina.com (Y.R.); youhaifei1987@163.com (H.Y.); wangby95@163.com (B.W.)

4 Division of Neurogenetics, Center for Neurological Diseases and Cancer, University Graduate School of Medicine, Nagoya 4668550, Japan; ohnok@med.nagoya-u.ac.jp

* Correspondence: gao_kp@szu.edu.cn (K.G.); tjwcj2005@126.com (C.W.); Tel.: +86-755-86671951 (K.G. \& C.W.); Fax: +86-755-86671906 (K.G. \& C.W.)

+ The authors contributed equally to this work

Academic Editor: Paul B. Tchounwou

Received: 15 September 2015; Accepted: 16 February 2016; Published: 26 February 2016

\begin{abstract}
Genetic variants at KCNQ1 rs151290, KLF14 rs972283, GCKR rs780094 and MTNR1B rs10830963 have been associated with type 2 diabetes mellitus (T2DM), but the results are contradictory in Chinese populations. The aim of the present study was to investigate the association of these four SNPs with T2DM in a large population of Han Chinese at Henan province, China. Seven-hundred-thirty-six patients with T2DM (cases) and Seven-hundred-sixty-eight healthy glucose-tolerant controls were genotyped for KCNQ1 rs151290, KLF14 rs972283, GCKR rs780094 and MTNR1B rs10830963. The association of genetic variants in these four genes with T2DM was analyzed using multivariate logistic regression. Genotypes and allele distributions of KCNQ1 rs151290 were significantly different between the cases and controls $(p<0.05)$. The AC and CC genotypes and the combined AC + CC genotype of rs151290 in KCNQ1 were associated with increases risk of T2DM before $(\mathrm{OR}=1.482,95 \% \mathrm{CI}=1.062-2.069 ; p=0.021 ; \mathrm{OR}=1.544,95 \% \mathrm{CI}=1.097-2.172, p=0.013$; and $\mathrm{OR}=1.509,95 \% \mathrm{CI}=1.097-2.077, p=0.011$, respectively $)$ and after $(\mathrm{OR}=1.539,95 \% \mathrm{CI}=1.015-2.332$, $p=0.042 ; \mathrm{OR}=1.641,95 \% \mathrm{CI}=1.070-2.516, p=0.023 ;$ and $\mathrm{OR}=1.582,95 \% \mathrm{CI}=1.061-2.358, p=0.024$; respectively) adjustment for sex, age, anthropometric measurements, biochemical indexes, smoking and alcohol consumption. Consistent with results of genotype analysis, the $C$ allele of rs151290 in $K C N Q 1$ was also associated with increased risk of T2DM $(\mathrm{OR}=1.166,95 \% \mathrm{CI}=1.004-1.355, p=0.045)$. No associations between genetic variants of KLF14 rs972283, GCKR rs780094 or MTNR1B rs10830963 and T2DM were detected. The AC and CC genotypes and the C allele of rs151290 in KCNQ1 may be risk factors for T2DM in Han Chinese in Henan province.
\end{abstract}

Keywords: single nucleotide polymorphism; KCNQ1; type 2 diabetes; risk factors 


\section{Introduction}

In recent years, the prevalence of diabetes mellitus (DM) has increased significantly in China. In September 2010, a large epidemiological survey [1] found that the prevalence of DM was 9.7\% in the Chinese population, suggesting that the overall prevalence of diabetes among nearly 100 million people in China was equivalent to $1 / 3$ of the prevalence worldwide. Among them, 90\% of the patients have type 2 diabetes mellitus (T2DM). There are many risk factors associated with developing T2DM, including obesity, unhealthy diet, older age, high blood pressure and family history of diabetes. A genetic background has also been shown to be correlated with T2DM risk. Gene polymorphism studies have revealed that multiple single nucleotide polymorphisms (SNPs) are involved in the development of T2DM. Therefore, genetic risk factors of T2DM need to be explored for T2DM prevention and treatment. Data from the genome-wide association studies (GWAS) [2,3] identified new genes associated with fasting glucose, insulin secretion and sensitivity. These recently identified genes include those in the potassium voltage-gated channel KQT-like subfamily, member 1 (KCNQ1) [4], glucokinase regulatory protein (GCKR), melatonin receptor 1B (MTNR1B) and Krüppel-like factor 14 (KLF14) [5]. Most studies suggest that KCNQ1rs151290, rs2237892, rs2237895 and rs2237897 polymorphisms are associated with susceptibility to T2DM such as those in Germany [4], China [6], Pakistan and the Netherlands [7,8]. However, the association was not found in Tunisian Arabs or in the Tuebingen Lifestyle Intervention Program in Germany [9,10]. GCKR rs780094 and MTNR1B rs10830963 were both identified in GWAS in European and Japanese populations [11,12]. The distribution of these two SNPs has also been studied in Chinese populations, but the results are inconsistent [13]. The variant KLF14 rs972283 may be a risk factor for metabolic disease and had a nominal association with T2DM in a Japanese population, but the association was not significant after Bonferroni's correction [14]. Although it has been mentioned that it is not risk factor for T2DM in Ningxia province, there may be differences between populations in different regions [15].

Therefore, each of the SNPs above may have different associations with T2DM in different populations. More evidence is currently needed to assess whether they are really a risk for T2DM in Chinese populations. In this study, we investigated these four recently identified SNPS KCNQ1 rs151290, KLF14 rs972283, GCKR rs780094 and MTNR1B rs10830963 in Han Chinese in Henan Province to determine their underlying genetic effects in relation to T2DM in this population.

\section{Methods}

\subsection{Ethics Statement}

The procedure of the study was approved by the Medical Ethics Committee, School of Medicine, Shenzhen University and Zhengzhou University Medical Ethics Committee (No. 2014-2-1310-001; 2014-3-1307-002), and written informed consent was obtained from all participants.

\subsection{Study Population}

The study population included 736 patients with T2DM and 768 healthy controls, randomly selected from an existing large case-control population from Henan Province, China [16]. The patients were recruited from The First Affiliated Hospital of Zhengzhou University and Henan Provincial Armed Police General Hospital. The healthy control population was recruited from the local communities of Xin'an County in Henan Province. All of the participants were from Northern Han Chinese backgrounds. Details of demographic characteristics of the study subjects were collected by interview in person using standard questionnaires [16]. For this study, smoking status was classified as smokers and non-smokers. Participants who currently smoked and/or had smoked at least 100 cigarettes during their lifetime were classified as smokers; Self-reported alcohol consumption was classified as consuming $100 \mathrm{~mL}$ liquor in 30 days. The clinical symptoms of diabetes were frequent urination, strong thirst, strong hunger even after having eaten, extreme fatigue, blurred vision, slow healing cuts or bruises tingling, pain, or numbness in the hands/feet. If these symptoms were present 
alongside fasting blood glucose $(\mathrm{FBG}) \geqslant 7.00 \mathrm{mmol} / \mathrm{L}$ or $2 \mathrm{~h}$ plasma glucose $\geqslant 11.0 \mathrm{mmol} / \mathrm{L}$ during an oral glucose tolerance test, then T2DM was diagnosed.

Patients were included if they were between 20 and 85 years old, and had been diagnosed with T2DM in accordance with 2005 American Diabetes Association criteria [17]. Participants were excluded if they had low body weight, malnutrition (body mass index $(\mathrm{BMI})<18.5$ ), were diagnosed with type 1 diabetes (fasting insulin $<5 \mu \mathrm{IU} / \mathrm{mL}$, fasting glucose $>6.8 \mathrm{mmol} / \mathrm{L}$ ) or other abnormal glucose tolerance, were pregnant, a physical disability, were mentally disturbed, obese (caused by disease), taking certain drugs which could induce obesity (exogenous corticosteroids such as prednisone and long-term oral contraceptives), or had cancer. We consecutively recruited controls from subjects when underwent regular physical examinations at the hospital. Healthy controls were selected on the following criteria: (1) aged between 25 and 75 years; (2) had no history of diabetes; (3) with normal FBG level, no abnormal glucose tolerance; (4) no other chronic diseases; and (5) no malnutrition or low body weight.

The subjects self-reported their ancestry. An interviewer-administered questionnaire was used to collect demographic and anthropometric characteristics.

\subsection{Clinical and Biochemical Measurements}

Body weight, height, waist circumference (WC), and blood pressure (systolic and diastolic: SBP and DBP) were collected as anthropometric data. Blood pressure was measured by an electronic sphygmomanometer. Fasting glucose, low-density lipoprotein cholesterol (LDL-C), high-density lipoprotein cholesterol (HDL-C), plasma total cholesterol (TC), and triglycerides (TG) were collected as laboratory measurements [18]. The "normal" levels of these measurements were defined by the following standards: $\mathrm{SBP}<140 \mathrm{mmHg}$, DBP $<90 \mathrm{mmHg}$, TC 3.35-6.45 mmol/L, TG 0.48-0.88 mmol/L, HDL-C 1.09-1.73 mmol/L and LDL-C 2.7-3.36 mmol/L.

\subsection{Sample Size Calculation}

The sample size for this case-control study was calculated with Sample Size Calculations software (Mark Woodward, The George Institute International Health; Lesley Francis, MIS Consultants Pty. Ltd., New South Wales, Australia).

Minor allele frequency (MAF) of the 4 SNPs (KCNQ1 rs151290, KLF14 rs972283, GCKR rs780094 and MTNR1B rs10830963) were reported to be $0.433,0.667,0.366$ and 0.634 , respectively, shown in Supplementary Table S1. $p_{0}=0.366$ was set based on the lowest MAF. With OR $=1.5, \alpha=0.05$ (two-tailed), $\beta=0.10$, the estimated sample size was 1058, with 529 for each group.

\subsection{SNP Selection and Genotyping}

A panel of 4 SNPs in 4 diabetes-associated genes were selected on the basis of the following criteria. (1) SNPs in genes that are known to be implicated in fasting glucose, insulin secretion and sensitivity; (2) SNPs previously reported to be associated with T2DM; (3) MAF $\geqslant 0.366$ in Chinese based on the International HapMap Project [19]; (4) Potentially functional SNPs (e.g., coding SNPs and SNPs in Untranslated Regions (UTR), promoter and splicing site).

Genotyping of all SNPs was performed using the TaqMan SNP Genotyping Fluorescence quantitative assays (Applied Biosystems, Foster City, CA, USA) in 2014. The DNA samples were processed in 384-well plates. The TaqMan genotyping reaction was amplified on a GeneAmp PCR system 7000, and fluorescence was detected on an ABI PRISM 7000 sequence detector (Applied Biosystems). The TaqMan Fluorescence SNP probes were synthesized by Life Technologies Biotech Co. (Foster, CA, USA). Overall, genotyping success rate was 100\% for rs151290, rs972283, rs780094 and rs 10830963 , and the error rate was $0 \%$ (Figure 1). To verify the reproducibility, we repeated $20 \%$ of samples at random as a quality control for genotyping, and the concordance rate was $100 \%$ (data not shown). Detailed characteristics of the 4 SNP probes are in Supplementary Table S2, and verification testing data are in Supplementary Table S3. 

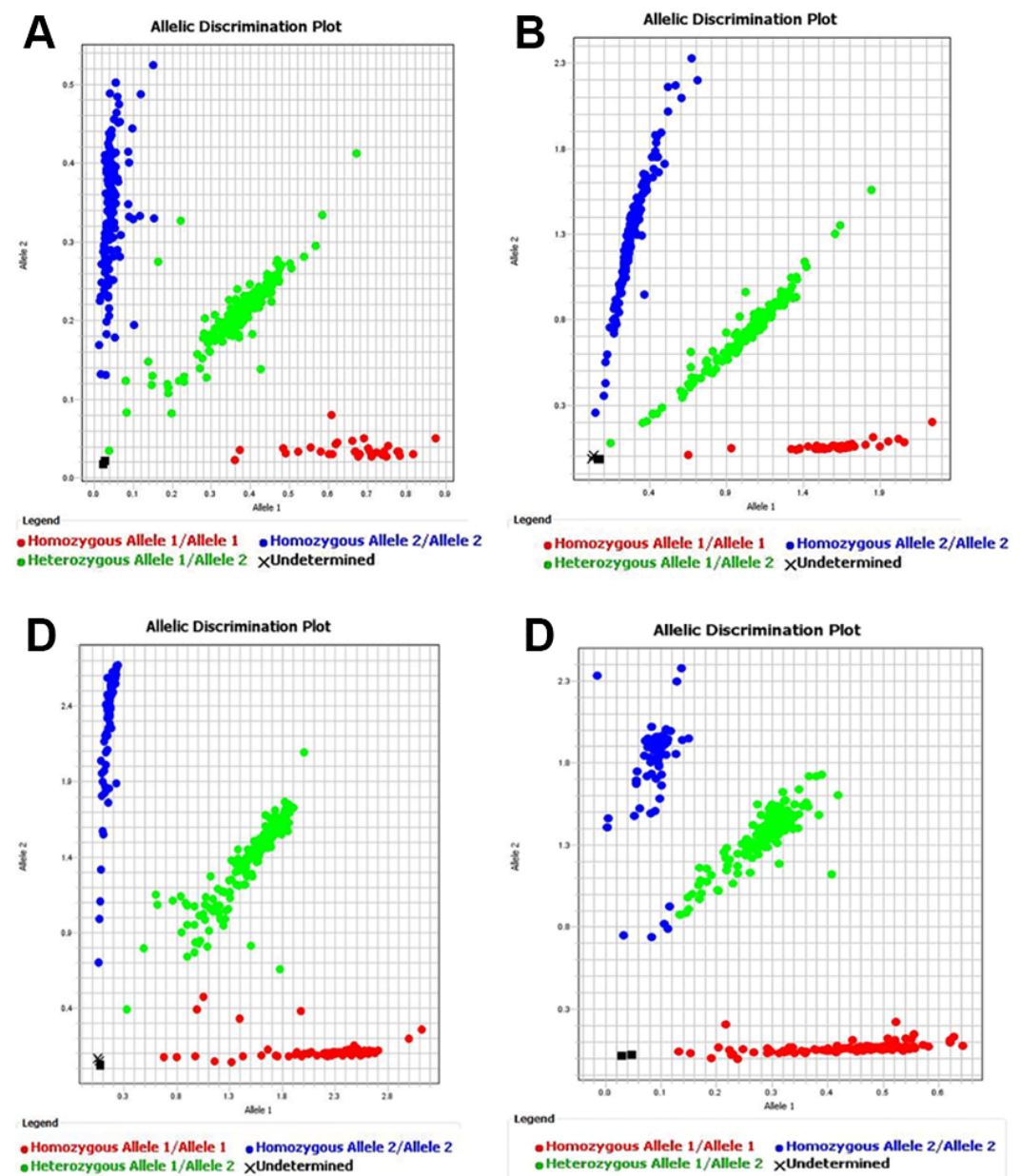

Figure 1. TaqMan single nucleotide polymorphism genotyping assay. (A) KCNQ1, rs151290, Context Sequence $[\mathrm{VIC} / \mathrm{FAM}]=[\mathrm{A} / \mathrm{C}]$; (B) KLF14, rs972283, Context Sequence [VIC/FAM] = [A/G]; (C) GCKR, rs780094, Context Sequence [VIC/FAM] $=[\mathrm{C} / \mathrm{T}]$ or $[\mathrm{A} / \mathrm{G}]$; (D) MTNR1B, rs10830963, Context Sequence $[\mathrm{VIC} / \mathrm{FAM}]=[\mathrm{C} / \mathrm{G}]$.

\subsection{Statistical Analysis}

Statistical analysis was performed using SPSS v17.0 for Windows (SPSS Inc., Chicago, IL, USA). The categorical variables are presented as the number and percentage that they were analyzed with by chi-square test. The continuous variables are presented by median values and the 25th, 75th quartile for non-normally distributed data. The differences between the patients and control populations were assessed by Mann-Whitney-Wilcoxon and Kruskal-Wallis rank tests. The Hardy-Weinberg equilibrium was calculated in controls using chi-square test, and each SNP was separately calculated for cases and controls by use of Fisher's exact test. Logistic regression analysis was used to calculate the odds ratios (ORs), 95\% confidence intervals (95\% CIs) and corresponding $p$ values for risk of T2DM after adjusting for gender, age, smoking, alcohol consumption, anthropometric measurements including BMI, WC and blood pressure and biochemical indexes including HDL-C, LDL-C, TC and TG levels. Multiplicative interaction terms were included in multivariate logistic regression models to assess the association of interactions between these 4 SNPs with T2DM development, adjusting for gender, age, BMI, smoking and alcohol consumption. The tests were all two-sided and were considered to be statistically significant if $p<0.05$. The power calculation was performed using PGA software [20]. 


\section{Results}

We included 736 T2DM patients (426 males) and 768 controls (324 males). Clinical characteristics of the case and control groups are shown in Table 1 and Supplementary Table S4. Compared with controls, diabetic patients had significantly higher anthropometric and metabolic measurements for BMI, WC, SBP, DBP, and TC, TG, LDL-C and HDL-C levels $(p<0.001)$ as well as age, gender $(p<0.001)$ and alcohol consumption $(p<0.006)$.

Table 1. Characteristics of type 2 diabetes mellitus (T2DM) cases and controls.

\begin{tabular}{|c|c|c|c|c|}
\hline Characteristics & Cases $(n=736)$ & Controls $(n=768)$ & $\mathrm{Z} / \chi^{2}$ & $p$ \\
\hline \multicolumn{5}{|l|}{ Gender* } \\
\hline Male & $426(57.88)$ & $324(42.19)$ & \multirow{2}{*}{37.018} & \multirow{2}{*}{$<0.001$} \\
\hline Female & $310(42.12)$ & $444(57.81)$ & & \\
\hline Age ${ }^{\#}$ & $52.50(43-61)$ & $47.00(39-57)$ & 6.212 & $<0.001$ \\
\hline $\mathrm{FBG}^{\#}$ & $7.04(5.73,9.21)$ & $5.19(4.92,5.50)$ & 24.350 & $<0.001$ \\
\hline $\mathrm{BMI}^{\#}\left(\mathrm{~kg} / \mathrm{m}^{2}\right)$ & $28.58(25.37,32.12)$ & $23.50(21.43,25.85)$ & 20.671 & $<0.001$ \\
\hline $\mathrm{WC}^{\#}(\mathrm{~cm})$ & $93.50(85.00,108.00)$ & $80.50(74.53,87.70)$ & 20.442 & $<0.001$ \\
\hline $\mathrm{SBP}^{\#}(\mathrm{mmHg})$ & $128.00(120.00,138.00)$ & $121.50(111.33,134.67)$ & 7.011 & $<0.001$ \\
\hline $\mathrm{DBP}^{\#}(\mathrm{mmHg})$ & $82.00(72.00,90.00)$ & $77.00(71.33,85.33)$ & 6.147 & $<0.001$ \\
\hline $\mathrm{TC}^{\#}(\mathrm{mmol} / \mathrm{L})$ & $4.87(4.29,5.59)$ & $4.30(3.70,4.91)$ & 12.398 & $<0.001$ \\
\hline $\mathrm{TG}^{\#}(\mathrm{mmol} / \mathrm{L})$ & $1.59(1.11,2.37)$ & $1.30(0.95,1.88)$ & 6.652 & $<0.001$ \\
\hline $\mathrm{HDL}^{-C^{\#}}(\mathrm{mmol} / \mathrm{L})$ & $1.09(0.96,1.25)$ & $1.15(0.99,1.32)$ & -3.378 & $<0.001$ \\
\hline $\mathrm{LDL}^{-C}{ }^{\#}(\mathrm{mmol} / \mathrm{L})$ & $3.03(2.55,3.69)$ & $2.40(1.93,2.90)$ & 16.713 & $<0.001$ \\
\hline \multicolumn{5}{|l|}{ Smoking * } \\
\hline Non-smoking & $536(48.73)$ & $565(51.27)$ & \multirow{2}{*}{0.124} & \multirow{2}{*}{0.725} \\
\hline Smoking & $20(49.75)$ & $203(50.25)$ & & \\
\hline \multicolumn{5}{|l|}{ alcohol consumption * } \\
\hline Non-drinking & $611(47.36)$ & $679(52.64)$ & \multirow[b]{2}{*}{7.601} & \multirow{2}{*}{0.0058} \\
\hline Drinking & $121(57.62)$ & $89(42.38)$ & & \\
\hline
\end{tabular}

The genotype and allele distributions of all four SNPs were in accordance with the Hardy-Weinberg equilibrium proportions in control $(p>0.1$ or $p<0.1$ and the sample size was large enough). The genotype and allele distribution of KCNQ1 rs151290 showed a difference between T2DM patients and healthy controls $(p<0.05)$ (Table 2).

Before and after adjusting for sex, age, anthropometric measurements, biochemical indexes, smoking and alcohol consumption, the AC and CC genotype and the combined AC + CC genotype of KCNQ1 rs151290 were significantly associated with higher risk of T2DM $(\mathrm{OR}=1.482,95 \% \mathrm{CI}=$ $1.062-2.069 ; 1.544,1.097-2.172 ; 1.509,1.097-2.077$; adjusted $\mathrm{OR}=1.539,95 \% \mathrm{CI}=1.015-2.332 ; 1.641$, $1.070-2.516 ; 1.582,1.061-2.358$, respectively; $p<0.05)$. The C allele of KCNQ1 rs151290 was also associated with increased risk of T2DM (OR $=1.166,95 \% \mathrm{CI}=1.004-1.355, p<0.05)$. However, the other three SNPs (KLF14 rs972283, GCKR rs780094 and MTNR1B rs10830963) were not found to be associated with T2DM $(p>0.05)$ in this Han people in Henan province, China (Table 3).

In the subsequent SNP-SNP interaction analysis, after adjustment for sex, age, BMI, smoking and alcohol consumption, interactions were found between GG genotype of rs10830963 and AG genotype of rs780094 from MTNR1B and GCKR (OR $=0.392,95 \% \mathrm{CI}=0.157-0.982, p=0.046)$, and CC genotype of rs151290 with AA genotype of rs780094 from KCNQ1 and GCKR (OR $=4.883,95 \% \mathrm{CI}=1.366-17.464$, $p=0.015$ ) in T2DM patients (Table 4). 
Table 2. Distribution of genotype and allele frequncy of 5 single nucleotide polymorphisms (SNPs) in T2DM cases and controls.

\begin{tabular}{|c|c|c|c|c|c|c|c|c|c|}
\hline \multirow{2}{*}{ SNP } & \multirow{2}{*}{ Genotype } & \multicolumn{2}{|c|}{$n$ for Genotype } & \multirow{2}{*}{$p(\mathrm{G}) *$} & \multirow{2}{*}{ Allele } & \multicolumn{2}{|c|}{$n$ for Allele } & \multirow{2}{*}{$p(\mathrm{~A}) *$} & \multirow{2}{*}{$p(\mathrm{HW})^{\#}$} \\
\hline & & Case & Control & & & Case & Control & & \\
\hline rs151290 (KCNQ1) & $\mathrm{AA} / \mathrm{AC} / \mathrm{CC}$ & $71 / 358 / 294$ & $107 / 364 / 287$ & 0.037 & $\mathrm{~A} / \mathrm{C}$ & $500 / 946$ & $578 / 938$ & 0.045 & 0.6237 \\
\hline rs972283 (KLF14) & $\mathrm{GG} / \mathrm{AG} / \mathrm{AA}$ & $379 / 286 / 56$ & $389 / 297 / 71$ & 0.540 & $\mathrm{G} / \mathrm{A}$ & $1044 / 398$ & $1075 / 439$ & 0.400 & 0.1942 \\
\hline rs780094 (GCKR) & $\mathrm{GG} / \mathrm{AG} / \mathrm{AA}$ & $194 / 343 / 185$ & $186 / 348 / 225$ & 0.204 & $\mathrm{G} / \mathrm{A}$ & $731 / 713$ & $720 / 798$ & 0.082 & 0.0264 \\
\hline rs10830963 (MTNR1B) & $\mathrm{CC} / \mathrm{CG} / \mathrm{GG}$ & $243 / 347 / 134$ & $280 / 350 / 129$ & 0.387 & $\mathrm{C} / \mathrm{G}$ & $833 / 615$ & $910 / 608$ & 0.181 & 0.2737 \\
\hline
\end{tabular}

${ }^{*}$ Fisher's exact test; ${ }^{\#}$ chi-square test; $p(\mathrm{G}): p$ for genotype; $p(\mathrm{~A}): p$ for allele; $p(\mathrm{HW}): p$ for Hardy-Weinberg equilibriumte in control.

Table 3. Association of genetic variants with type 2 diabetes.

\begin{tabular}{|c|c|c|c|c|c|c|}
\hline SNP & Genetic Model & Cases/Controls & OR $(95 \% \mathrm{CI})$ & $p$ & Adjusted OR $(95 \%$ CI $) *$ & Adjusted $p^{*}$ \\
\hline rs151290 & Genotype & & & & & \\
\hline \multirow[t]{12}{*}{ (KCNQ1) } & AA & $71 / 107$ & 1.000 & & 1.000 & \\
\hline & $\mathrm{AC}$ & $358 / 364$ & $1.482(1.062-2.069)$ & 0.021 & $1.539(1.015-2.332)$ & 0.042 \\
\hline & CC & $294 / 287$ & $1.544(1.097-2.172)$ & 0.013 & $1.641(1.070-2.516)$ & 0.023 \\
\hline & Dominant model & & & & & \\
\hline & AA & $71 / 107$ & 1.000 & & & \\
\hline & $\mathrm{AC}+\mathrm{CC}$ & $652 / 651$ & $1.509(1.097-2.077)$ & 0.011 & $1.582(1.061-2.358)$ & 0.024 \\
\hline & Recessive model & & & & & \\
\hline & $\mathrm{AA}+\mathrm{AC}$ & $429 / 471$ & 1.000 & & 1.000 & \\
\hline & CC & $294 / 287$ & $1.125(0.913-1.386)$ & 0.270 & $1.154(0.893-1.491)$ & 0.275 \\
\hline & Allele & & & & & \\
\hline & A & $500 / 578$ & 1.000 & & & \\
\hline & C & $946 / 938$ & $1.166(1.004-1.355)$ & 0.045 & & \\
\hline rs972283 & Genotype & & & & & \\
\hline \multirow[t]{10}{*}{$(K L F 14)$} & GG & $379 / 389$ & 1.000 & & 1.000 & \\
\hline & AG & $286 / 297$ & $0.988(0.797-1.226)$ & 0.915 & $0.901(0.692-1.173)$ & 0.438 \\
\hline & AA & $56 / 71$ & $0.810(0.555-1.181)$ & 0.273 & $0.734(0.458-1.176)$ & 0.199 \\
\hline & Dominant model & & & & & \\
\hline & GG & $379 / 389$ & 1.000 & & 1.000 & \\
\hline & $\mathrm{AG}+\mathrm{AA}$ & $342 / 368$ & $0.954(0.778-1.170)$ & 0.650 & $0.870(0.677-1.118)$ & 0.275 \\
\hline & Recessive model & & & & & \\
\hline & $\mathrm{GG}+\mathrm{AG}$ & $665 / 686$ & 1.000 & & 1.000 & \\
\hline & AA & $56 / 71$ & $0.814(0.564-1.173)$ & 0.270 & $0.768(0.486-1.213)$ & 0.258 \\
\hline & Allele & & & & & \\
\hline
\end{tabular}


Table 3. Cont

\begin{tabular}{|c|c|c|c|c|c|c|}
\hline SNP & Genetic Model & Cases/Controls & OR $(95 \% \mathrm{CI})$ & $p$ & Adjusted OR $(95 \% \mathrm{CI})$ * & Adjusted $p^{*}$ \\
\hline & G & $1044 / 1075$ & 1.000 & & & \\
\hline & A & $398 / 439$ & $0.934(0.795-1.096)$ & 0.400 & & \\
\hline rs780094 & Genotype & & & & & \\
\hline \multirow[t]{12}{*}{$(G C K R)$} & GG & 194/186 & 1.000 & & 1.000 & \\
\hline & AG & $343 / 348$ & $0.945(0.736-1.214)$ & 0.658 & $1.090(0.800-1.485)$ & 0.585 \\
\hline & AA & $185 / 225$ & $0.788(0.596-1.043)$ & 0.096 & $0.863(0.610-1.221)$ & 0.404 \\
\hline & Dominant model & & & & & \\
\hline & GG & $194 / 186$ & 1.000 & & 1.000 & \\
\hline & $\mathrm{AG}+\mathrm{AA}$ & $528 / 573$ & $0.883(0.700-1.116)$ & 0.298 & $1.001(0.749-1.338)$ & 0.994 \\
\hline & Recessive model & & & & & \\
\hline & $\mathrm{GG}+\mathrm{AG}$ & $537 / 534$ & 1.000 & & 1.000 & \\
\hline & AA & $185 / 225$ & $0.818(0.651-1.027)$ & 0.084 & $0.815(0.615-1.079)$ & 0.153 \\
\hline & Allele & & & & & \\
\hline & G & $731 / 720$ & 1.000 & & & \\
\hline & A & $713 / 798$ & $0.880(0.762-1.017)$ & 0.082 & & \\
\hline rs10830963 & Genotype & & & & & \\
\hline \multirow[t]{12}{*}{$(M T N R 1 B)$} & CC & $243 / 280$ & 1.000 & & 1.000 & \\
\hline & CG & $347 / 350$ & $1.142(0.910-1.433)$ & 0.251 & $1.026(0.775-1.357)$ & 0.858 \\
\hline & GG & $134 / 129$ & $1.197(0.890-1.610)$ & 0.235 & $1.128(0.788-1.615)$ & 0.510 \\
\hline & Dominant model & & & & & \\
\hline & CC & $243 / 280$ & 1.000 & & 1.000 & \\
\hline & CG + GG & $481 / 479$ & $1.157(0.935-1.432)$ & 0.181 & $1.054(0.811-1.370)$ & 0.694 \\
\hline & Recessive model & & & & & \\
\hline & $\mathrm{CC}+\mathrm{CG}$ & $590 / 630$ & 1.000 & & 1.000 & \\
\hline & GG & $134 / 129$ & $1.109(0.850-1.448)$ & 0.446 & $1.112(0.807-1.532)$ & 0.517 \\
\hline & Allele & & & & & \\
\hline & C & $833 / 910$ & 1.000 & & & \\
\hline & G & $615 / 608$ & $1.105(0.955-1.279)$ & 0.181 & & \\
\hline
\end{tabular}


Table 4. The impact of interaction among SNPs on the risk of type 2 diabetes mellitus.

\begin{tabular}{|c|c|c|c|c|c|c|c|c|c|c|}
\hline \multirow{3}{*}{ SNP * } & \multirow{3}{*}{ Genotype } & \multicolumn{9}{|c|}{ SNP * } \\
\hline & & \multicolumn{3}{|c|}{ rs10830963 (MTNR1B) } & \multicolumn{3}{|c|}{ rs151290 (KCNQ1) } & \multicolumn{3}{|c|}{ rs972283 (KLF14) } \\
\hline & & $\mathrm{CC}$ & CG & GG & AA & $\mathrm{AC}$ & $\mathrm{CC}$ & GG & AG & AA \\
\hline \multirow{3}{*}{$\begin{array}{c}\text { rs780094 } \\
(\text { GCKR) }\end{array}$} & GG & 1 (Reference) & $\begin{array}{c}1.113 \\
(0.389-3.180) \\
0.842 \\
\end{array}$ & $\begin{array}{c}2.347 \\
(0.626-8.791) \\
0.206 \\
\end{array}$ & 1 (Reference) & $\begin{array}{c}0.567 \\
(0.193-1.671) \\
0.304\end{array}$ & $\begin{array}{c}0.466 \\
(0.157-1.382) \\
0.169\end{array}$ & 1 (Reference) & $\begin{array}{c}1.044 \\
(0.379-2.878) \\
0.933\end{array}$ & $\begin{array}{c}1.822 \\
(0.085-38.920) \\
0.701\end{array}$ \\
\hline & AG & $\begin{array}{c}1.170 \\
(0.401-3.420) \\
0.774\end{array}$ & $\begin{array}{c}0.655 \\
(0.313-1.368) \\
0.260\end{array}$ & $\begin{array}{c}0.392 \\
(0.157-0.982) \\
0.046\end{array}$ & $\begin{array}{c}1.170 \\
(0.401-3.420) \\
0.774\end{array}$ & $\begin{array}{c}0.976 \\
(0.331-2.875) \\
0.965\end{array}$ & $\begin{array}{c}1.153 \\
(0.383-3.472) \\
0.800\end{array}$ & $\begin{array}{c}1.170 \\
(0.401-3.420) \\
0.774\end{array}$ & $\begin{array}{c}1.004 \\
(0.513-1.965) \\
0.991\end{array}$ & $\begin{array}{c}3.393 \\
(0.955-12.055) \\
0.059\end{array}$ \\
\hline & $\mathrm{AA}$ & $\begin{array}{c}0.396 \\
(0.115-1.362) \\
0.142 \\
\end{array}$ & $\begin{array}{c}1.304 \\
(0.569-2.986) \\
0.531 \\
\end{array}$ & $\begin{array}{c}0.442 \\
(0.156-1.249) \\
0.124\end{array}$ & $\begin{array}{c}0.396 \\
(0.115-1.362) \\
0.142\end{array}$ & $\begin{array}{c}2.265 \\
(0.657-7.812) \\
0.196\end{array}$ & $\begin{array}{c}4.883 \\
(1.366-17.464) \\
0.015\end{array}$ & $\begin{array}{c}0.396 \\
(0.115-1.362) \\
0.142\end{array}$ & $\begin{array}{c}1.245 \\
(0.583-2.659) \\
0.571\end{array}$ & $\begin{array}{c}2.583 \\
(0.672-9.934) \\
0.167\end{array}$ \\
\hline \multirow[t]{3}{*}{$\begin{array}{l}\text { rs151290 } \\
\text { (KCNQ1) }\end{array}$} & $\mathrm{AA}$ & 1 (Reference) & $\begin{array}{c}1.113 \\
(0.389-3.180) \\
0.842 \\
\end{array}$ & $\begin{array}{c}2.347 \\
(0.626-8.791) \\
0.206 \\
\end{array}$ & - & - & - & - & - & - \\
\hline & $\mathrm{AC}$ & $\begin{array}{c}0.567 \\
(0.193-1.671) \\
0.304 \\
\end{array}$ & $\begin{array}{c}1.046 \\
(0.400-2.738) \\
0.927 \\
\end{array}$ & $\begin{array}{c}0.721 \\
(0.217-2.396) \\
0.594\end{array}$ & - & - & - & - & - & - \\
\hline & $\mathrm{CC}$ & $\begin{array}{c}0.466 \\
(0.157-1.382) \\
0.169 \\
\end{array}$ & $\begin{array}{c}0.905 \\
(0.336-2.438) \\
0.844 \\
\end{array}$ & $\begin{array}{c}0.521 \\
(0.151-1.797) \\
0.302 \\
\end{array}$ & - & - & - & - & - & - \\
\hline \multirow{3}{*}{$\begin{array}{c}\text { rs972283 } \\
\text { (KLF14) }\end{array}$} & GG & 1 (Reference) & $\begin{array}{c}1.113 \\
(0.389-3.180) \\
0.842 \\
\end{array}$ & $\begin{array}{c}2.347 \\
(0.626-8.791) \\
0.206 \\
\end{array}$ & 1 (Reference) & $\begin{array}{c}0.567 \\
(0.193-1.671) \\
0.304\end{array}$ & $\begin{array}{c}0.466 \\
(0.157-1.382) \\
0.169\end{array}$ & - & - & - \\
\hline & AG & $\begin{array}{c}1.044 \\
(0.379-2.878) \\
0.933 \\
\end{array}$ & $\begin{array}{c}0.801 \\
(0.437-1.467) \\
0.472 \\
\end{array}$ & $\begin{array}{c}1.133 \\
(0.512-2.508) \\
0.757\end{array}$ & $\begin{array}{c}1.044 \\
(0.379-2.878) \\
0.933\end{array}$ & $\begin{array}{c}1.034 \\
(0.426-2.510) \\
0.942 \\
\end{array}$ & $\begin{array}{c}1.128 \\
(0.452-2.814) \\
0.796 \\
\end{array}$ & - & - & - \\
\hline & AA & $\begin{array}{c}1.822 \\
(0.085-38.920) \\
0.701\end{array}$ & $\begin{array}{c}1.940 \\
(0.627-6.002) \\
0.250\end{array}$ & $\begin{array}{c}1.986 \\
(0.482-8.187) \\
0.343\end{array}$ & $\begin{array}{c}1.822 \\
(0.085-38.920) \\
0.701\end{array}$ & $\begin{array}{c}0.204 \\
(0.011-3.892) \\
0.291\end{array}$ & $\begin{array}{c}0.222 \\
(0.011-4.495) \\
0.327\end{array}$ & - & - & - \\
\hline
\end{tabular}

Data are OR $(95 \% \mathrm{CI}), p$ value; ${ }^{*}$ data are adjusted for sex, age, body mass index, smoking and alcohol consumption; $p$ value for testing effect of modification by behavior risk factors using an interaction term of status of $b$ 


\section{Discussion}

The aim of this investigation was to analyze the association of KCNQ1 rs151290, KLF14 rs972283, GCKR rs780094 and MTNR1B rs10830963 polymorphisms with T2DM in Han Chinese people in Henan province, China. Our findings reveal an association of genetic variants of the KCNQ1 rs151290 SNP and increased risk of T2DM in this population. Furthermore, we found that interactions among KLF14 rs972283, GCKR rs780094 and MTNR1B rs10830963 were also associated with T2DM.

Variants in KCNQ1 (the rs151290, rs2237892, rs2237895 and rs2237897 polymorphisms) are suggested to be associated with susceptibility to T2DM through affecting upon incretin and insulin secretion [4]. The rs2237892 CC/TC genotype was related to first- and second-phase insulin secretion in Chinese studies [6]. While the C allele of rs151290 in KCNQ1 (located within intron 16) has been significantly associated with reduced first-phase glucose-stimulated insulin secretion in different populations [8,21], it may also be associated with lipid metabolism [21]. However, not all studies have found an association between rs151290 and T2DM [9,10]. We found the AC and CC genotype and the combined genotype AC + CC of KCNQ1 rs151290 was associated with T2DM, and the C allele of KCNQ1 rs151290 was also associated with T2DM before adjusting for gender, age, anthropometric measurements, biochemical indexes, smoking and alcohol consumption. According to previous study, the risk allele C of rs151290 in KCNQ1 was associated with increased risk of T2DM in a global population. However, results from studies in several different regions in China, including Hebei, Kunming and Huaihai, were not in agreement with that data from another study in Hebei province [15]. Hebei is a province next to Henan province in China. The similarity of study results between us and that in Hebei may indicate the influence of other risk factors, including lifestyle and genetic background and may affect the association of KCNQ1 rs151290 and T2DM.

Associations between KLF14 and T2DM are found in some populations but not in others. In this study, there was no significant association of rs972283 and T2DM, which may be consistent with the result from research by Long et al. [22] in African Americans, but is not in accordance with research by Ohshige et al. [23] in Japan, Voight et al. [2] in Europe and Rees et al. [7] in Pakistan. In the Japanese population studied by Ohshige et al., the association of risk allele G of KLF14 rs972283 and T2DM vanished after being adjusted for sex, age and log-transformed BMI, and there seemed to be no significant association between KLF14 rs972283 and glucose metabolism [23]. The present study also did not detect the association between KLF14 rs972283 with T2DM, leaving the genotype as a yet-to-confirm risk factor of the disease.

GCKR rs780094 is associated with elevated fasting serum triacylglycerol, and reduced fasting insulin secretion, which reduces the risk of T2DM [24]. The GCKR rs780094 A allele may decrease insulin secretion and reduce plasma glucose and TG levels, thereby reducing the risk of T2DM $[3,25,26]$. However, these results were not confirmed by another study T2DM in a Chinese population [13]. GCKR rs780094 polymorphism was shown to be associated with T2DM in Asian populations. In a Japanese population, it was revealed that the rs780094 G allele was closely related to the pathogenesis of T2DM, increased fasting insulin and reduced TG levels, with the A allele associated with low fasting glucose and high TG levels [12]. It has been shown that the T allele of GCKR rs780094 is associated with increased blood glucose levels, insulin secretion, TG levels and incidence of T2DM in a German population [11]. However, studies in the Chinese Han population have not reached the same conclusion of an association of rs780094 with T2DM islet $\beta$-cell function $[27,28]$. Two studies investigated the association of GCKR rs780094 and T2DM: one in 2009 in Beijing showed that the G allele was a risk factor of T2DM, and the A allele may increase $\beta$-cell function [29]; the other study, in 2011 in Shanghai, found no association of the $G$ allele and T2DM, but the authors did not check $\beta$-cell function and insulin resistance [27]. Our data showed no direct association with T2DM, but we found that, when interacting with GG genotype of MTNR1B rs10830963, the AG genotype of rs780094 may be a protective factor.

MTNR1B rs10830963 is significantly associated with decreased $\beta$ cell function or increased fasting plasma glucose [28,30,31]; studies in Japanese [32] and Mexican Americans [33] have confirmed the similar results. In relation to the decreased $\beta$ cell function, there seems to be a particular relationship 
with this polymorphism and the development of gestational diabetes in pregnant women [34], which was also found in a Chinese population [35]. From 2009 to 2010, the association in China was investigated; MTNR1B was genotyped in residents of Shanghai: all three studies showed MTNR1B rs10830963 was associated with elevated FPG and impaired insulin secretion [28,30,36], similar to a Hong Kong report [31]. Hu et al. reported that the MTNR1B genetic variantswere associated with first-phase but not second-phase insulin secretion [36]. However, Liu et al. reported that MTNR1B rs10830963 was associated with fasting glucose and $\beta$-cell function in the Shanghai but not in a Beijing subpopulation [30]. Therefore, MTNR1B rs10830963 research in China has not produced consistent results. Our data complements and increases the population information for different regions in China, as we did not detect an association with T2DM. This suggests that the CG genotype of MTNR1B rs10830963 is not associated with T2DM in Han Chinese in the Henan province, similar to results from residents of Beijing [30]. However, the lack of an association might be affected by the sample size of the study and other confounding factors, so more detailed analysis is required to support this finding.

The suggestion that differences in the associations of these polymorphisms with T2DM may vary with different populations within China may seem surprising. However, a study of more than 6000 Han Chinese from 10 provinces in China showed differences between northern and southern residents, with geographic disparities in DNA [37]. In addition, China is divided into north and south approximately by the Yangtze River, and the environment, diet structures and lifestyles differ greatly, which might also explain the inconsistent results. Therefore, it is not strange that differences occur between North and South China, such as Beijing, Shanghai and Hong Kong, with the association of SNPs (GCKR rs780094 and MTNR1B rs10830963) with T2DM, as has been reported [15,28-30].

\section{Conclusions}

In conclusion, our findings suggest that genotype and allele distributions of KCNQ1 rs151290 are different between T2DM patients and controls, and the variant genotypes and allele KCNQ1 rs151290 are associated with increased risk of T2DM in Han Chinese people in Henan province, China. In addition, there may be interactions between AG, GG and CG genotypes of KLF14 rs972283, GCKR rs780094 and MTNR1B rs10830963.

Supplementary Materials: The following are available online at www.mdpi.com/1660-4601/13/3/260/s1. Table S1: Single nucleotide polymorphisms (SNPs) selected for study in Han Chinese in Henan province, China. Table S2: Single nucleotide polymorphism (SNP) probes used for genotyping. Table S3: Verification primers. Table S4: Clinical characteristics of T2DM cases and controls in terms of biochemical measurements (SBP, DBP, TC, TG, HDL-C, LDL-C).

Acknowledgments: This study was supported by the National Natural Science Foundation of China (grant no. 81373074), the Natural Science Foundation of Guangdong Province (grant no. S2013010016791), the Science and Technology Development Foundation of Shenzhen (grant nos. JCYJ20130326110246234 and JCYJ20130326112522124), the Natural Science Foundation of Shenzhen University (grant no. 801-00035911) and the Doctoral Research Fund of Henan Chinese Medicine (grant no. BSJJ2014-18).

Author Contributions: Kaiping Gao, Chongjian Wang and Jinjin Wang designed the study, analyzed data, and drafted the manuscript. Haifei You, Bingyuan Wang, Xuli Wu, Jianna Li, Zichen Liu, Xiong Li, Yaxin Huang and Xin-Ping Luo extracted data and perform the experiments. Linlin Li, Yujia Zhai, Yongcheng Ren and Dongsheng Hu conducted data statistical analysis. Kinji Ohno polished the manuscript. All authors approved the final manuscript.

Conflicts of Interest: The authors declare that they have no conflict of interest.

\section{References}

1. Yang, S.H.; Dou, K.F.; Song, W.J. Prevalence of diabetes among men and women in China. N. Engl. J. Med. 2010, 362, 2425-2426. [CrossRef] [PubMed]

2. Voight, B.F.; Scott, L.J.; Steinthorsdottir, V.; Morris, A.P.; Dina, C.; Welch, R.P.; Zeggini, E.; Huth, C.; Aulchenko, Y.S.; Thorleifsson, G.; et al. Twelve type 2 diabetes susceptibility loci identified through large-scale association analysis. Nat. Genet. 2010, 42, 579-589. [CrossRef] [PubMed] 
3. Saxena, R.; Hivert, M.F.; Langenberg, C.; Tanaka, T.; Pankow, J.S.; Vollenweider, P.; Lyssenko, V.; Bouatia-Naji, N.; Dupuis, J.; Jackson, A.U.; et al. Genetic variation in GIPR influences the glucose and insulin responses to an oral glucose challenge. Nat. Genet. 2010, 42, 142-148. [CrossRef] [PubMed]

4. Mussig, K.; Staiger, H.; Machicao, F.; Kirchhoff, K.; Guthoff, M.; Schafer, S.A.; Kantartzis, K.; Silbernagel, G.; Stefan, N.; Holst, J.J.; et al. Association of type 2 diabetes candidate polymorphisms in KCNQ1 with incretin and insulin secretion. Diabetes 2009, 58, 1715-1720. [CrossRef] [PubMed]

5. Dimas, A.S.; Lagou, V.; Barker, A.; Knowles, J.W.; Magi, R.; Hivert, M.F.; Benazzo, A.; Rybin, D.; Jackson, A.U.; Stringham, H.M.; et al. Impact of type 2 diabetes susceptibility variants on quantitative glycemic traits reveals mechanistic heterogeneity. Diabetes 2014, 63, 2158-2171. [CrossRef] [PubMed]

6. Lu, S.; Xie, Y.; Lin, K.; Li, S.; Zhou, Y.; Ma, P.; Lv, Z.; Zhou, X. Genome-wide association studies-derived susceptibility loci in type 2 diabetes: Confirmation in a Chinese population. Clin. Invest. Med. 2012, 35, E327. [PubMed]

7. Rees, S.D.; Hydrie, M.Z.; Shera, A.S.; Kumar, S.; O'Hare, J.P.; Barnett, A.H.; Basit, A.; Kelly, M.A. Replication of 13 genome-wide association (GWA)-validated risk variants for type 2 diabetes in Pakistani populations. Diabetologia 2011, 54, 1368-1374. [CrossRef] [PubMed]

8. Van Vliet-Ostaptchouk, J.V.; Van Haeften, T.W.; Landman, G.W.; Reiling, E.; Kleefstra, N.; Bilo, H.J.; Klungel, O.H.; De Boer, A.; Van Diemen, C.C.; Wijmenga, C.; et al. Common variants in the type 2 diabetes KCNQ1 gene are associated with impairments in insulin secretion during hyperglycaemic glucose clamp. PLOS ONE 2012, 7, e32148.

9. Turki, A.; Mtiraoui, N.; Al-Busaidi, A.S.; Khirallah, M.; Mahjoub, T.; Almawi, W.Y. Lack of association between genetic polymorphisms within KCNQ1 locus and type 2 diabetes in Tunisian Arabs. Diabetes Res. Clin. Pract. 2012, 98, 452-458. [CrossRef] [PubMed]

10. Heni, M.; Ketterer, C.; Thamer, C.; Herzberg-Schafer, S.A.; Guthoff, M.; Stefan, N.; Machicao, F.; Staiger, H.; Fritsche, A.; Haring, H.U. Glycemia determines the effect of type 2 diabetes risk genes on insulin secretion. Diabetes 2010, 59, 3247-3252. [CrossRef] [PubMed]

11. Kozian, D.H.; Barthel, A.; Cousin, E.; Brunnhofer, R.; Anderka, O.; Marz, W.; Bohm, B.; Winkelmann, B.; Bornstein, S.R.; Schmoll, D. Glucokinase-activating GCKR polymorphisms increase plasma levels of triglycerides and free fatty acids, but do not elevate cardiovascular risk in the Ludwigshafen Risk and Cardiovascular Health Study. Horm. Metab. Res. 2010, 42, 502-506. [CrossRef] [PubMed]

12. Onuma, H.; Tabara, Y.; Kawamoto, R.; Shimizu, I.; Kawamura, R.; Takata, Y.; Nishida, W.; Ohashi, J.; Miki, T.; Kohara, K.; et al. The GCKR rs780094 polymorphism is associated with susceptibility of type 2 diabetes, reduced fasting plasma glucose levels, increased triglycerides levels and lower HOMA-IR in Japanese population. J. Hum. Genet. 2010, 55, 600-604. [CrossRef] [PubMed]

13. Qi, Q.; Wu, Y.; Li, H.; Loos, R.J.; Hu, F.B.; Sun, L.; Lu, L.; Pan, A.; Liu, C.; Wu, H.; et al. Association of GCKR rs780094, alone or in combination with GCK rs1799884, with type 2 diabetes and related traits in a Han Chinese population. Diabetologia 2009, 52, 834-843. [CrossRef] [PubMed]

14. Small, K.S.; Hedman, A.K.; Grundberg, E.; Nica, A.C.; Thorleifsson, G.; Kong, A.; Thorsteindottir, U.; Shin, S.Y.; Richards, H.B.; Consortium, G.; et al. Identification of an imprinted master trans regulator at the KLF14 locus related to multiple metabolic phenotypes. Nat. Genet. 2011, 43, 561-564. [CrossRef] [PubMed]

15. Wang, J.; Zhang, J.; Shen, J.; Hu, D.; Yan, G.; Liu, X.; Xu, X.; Pei, L.; Li, Y.; Sun, C. Association of KCNQ1 and KLF14 polymorphisms and risk of type 2 diabetes mellitus: A global meta-analysis. Hum. Immunol. 2014, 75, 342-347. [CrossRef] [PubMed]

16. Li, L.; Gao, K.; Zhao, J.; Feng, T.; Yin, L.; Wang, J.; Wang, C.; Li, C.; Wang, Y.; Wang, Q.; et al. Glucagon gene polymorphism modifies the effects of smoking and physical activity on risk of type 2 diabetes mellitus in Han Chinese. Gene 2014, 534, 352-355. [CrossRef] [PubMed]

17. American Diabetes, Association. Diagnosis and classification of diabetes mellitus. Diabetes Care 2005, 28 (Suppl. 1), S37-S42.

18. Joint Committee on formulation of China adult dyslipidemia Prevention Guide. China adult dyslipidemia prevention guide. Chin. J. Cardiol. 2007, 35, 401-404.

19. The International HapMap Project. Available online: http://www.hapmap.org (accessed on 11 February 2014).

20. Power for Genetic Association Analyses (PGA). Available online: http://dceg.cancer.gov/bb/tools/pga (accessed on 6 December 2014). 
21. Yasuda, K.; Miyake, K.; Horikawa, Y.; Hara, K.; Osawa, H.; Furuta, H.; Hirota, Y.; Mori, H.; Jonsson, A.; Sato, Y.; et al. Variants in KCNQ1 are associated with susceptibility to type 2 diabetes mellitus. Nat. Genet. 2008, 40, 1092-1097. [CrossRef] [PubMed]

22. Long, J.; Edwards, T.; Signorello, L.B.; Cai, Q.; Zheng, W.; Shu, X.O.; Blot, W.J. Evaluation of genome-wide association study-identified type 2 diabetes loci in African Americans. Am. J. Epidemiol. 2012, 176, 995-1001. [CrossRef] [PubMed]

23. Ohshige, T.; Iwata, M.; Omori, S.; Tanaka, Y.; Hirose, H.; Kaku, K.; Maegawa, H.; Watada, H.; Kashiwagi, A.; Kawamori, R.; et al. Association of new loci identified in European genome-wide association studies with susceptibility to type 2 diabetes in the Japanese. PLoS ONE 2011, 6, e26911. [CrossRef] [PubMed]

24. Sparso, T.; Andersen, G.; Nielsen, T.; Burgdorf, K.S.; Gjesing, A.P.; Nielsen, A.L.; Albrechtsen, A.; Rasmussen, S.S.; Jorgensen, T.; Borch-Johnsen, K.; et al. The GCKR rs780094 polymorphism is associated with elevated fasting serum triacylglycerol, reduced fasting and OGTT-related insulinaemia, and reduced risk of type 2 diabetes. Diabetologia 2008, 51, 70-75. [CrossRef] [PubMed]

25. Vaxillaire, M.; Cavalcanti-Proenca, C.; Dechaume, A.; Tichet, J.; Marre, M.; Balkau, B.; Froguel, P.; Group, D.S. The common P446L polymorphism in GCKR inversely modulates fasting glucose and triglyceride levels and reduces type 2 diabetes risk in the DESIR prospective general French population. Diabetes 2008, 57, 2253-2257. [CrossRef] [PubMed]

26. Orho-Melander, M.; Melander, O.; Guiducci, C.; Perez-Martinez, P.; Corella, D.; Roos, C.; Tewhey, R.; Rieder, M.J.; Hall, J.; Abecasis, G.; et al. Common missense variant in the glucokinase regulatory protein gene is associated with increased plasma triglyceride and C-reactive protein but lower fasting glucose concentrations. Diabetes 2008, 57, 3112-3121. [CrossRef] [PubMed]

27. Ling, Y.; Li, X.; Gu, Q.; Chen, H.; Lu, D.; Gao, X. Associations of common polymorphisms in GCKR with type 2 diabetes and related traits in a Han Chinese population: A case-control study. BMC Med. Genet. 2011, 12, 66. [CrossRef] [PubMed]

28. Ronn, T.; Wen, J.; Yang, Z.; Lu, B.; Du, Y.; Groop, L.; Hu, R.; Ling, C. A common variant in MTNR1B, encoding melatonin receptor $1 \mathrm{~B}$, is associated with type 2 diabetes and fasting plasma glucose in Han Chinese individuals. Diabetologia 2009, 52, 830-833. [CrossRef] [PubMed]

29. Ye, X.; Yu, Z.; Li, H.; Franco, O.H.; Liu, Y.; Lin, X. Distributions of C-reactive protein and its association with metabolic syndrome in middle-aged and older Chinese people. J. Am. Coll. Cardiol. 2007, 49, 1798-1805. [CrossRef] [PubMed]

30. Liu, C.; Wu, Y.; Li, H.; Qi, Q.; Langenberg, C.; Loos, R.J.; Lin, X. MTNR1B rs10830963 is associated with fasting plasma glucose, HbA1C and impaired beta-cell function in Chinese Hans from Shanghai. BMC Med. Genet. 2010, 11, 59. [CrossRef] [PubMed]

31. Tam, C.H.; Ho, J.S.; Wang, Y.; Lee, H.M.; Lam, V.K.; Germer, S.; Martin, M.; So, W.Y.; Ma, R.C.; Chan, J.C.; et al. Common polymorphisms in MTNR1B, G6PC2 and GCK are associated with increased fasting plasma glucose and impaired beta-cell function in Chinese subjects. PLoS ONE 2010, 5, e11428. [CrossRef] [PubMed]

32. Fujita, H.; Hara, K.; Shojima, N.; Horikoshi, M.; Iwata, M.; Hirota, Y.; Tobe, K.; Seino, S.; Kadowaki, T. Variations with modest effects have an important role in the genetic background of type 2 diabetes and diabetes-related traits. J. Hum. Genet. 2012, 57, 776-779. [CrossRef] [PubMed]

33. Ren, J.; Xiang, A.H.; Trigo, E.; Takayanagi, M.; Beale, E.; Lawrence, J.M.; Hartiala, J.; Richey, J.M.; Allayee, H.; Buchanan, T.A.; et al. Genetic variation in MTNR1B is associated with gestational diabetes mellitus and contributes only to the absolute level of beta cell compensation in Mexican Americans. Diabetologia 2014, 57, 1391-1399. [CrossRef] [PubMed]

34. Vlassi, M.; Gazouli, M.; Paltoglou, G.; Christopoulos, P.; Florentin, L.; Kassi, G.; Mastorakos, G. The rs10830963 variant of melatonin receptor MTNR1B is associated with increased risk for gestational diabetes mellitus in a Greek population. Hormones 2012, 11, 70-76. [PubMed]

35. Li, C.; Qiao, B.; Zhan, Y.; Peng, W.; Chen, Z.J.; Sun, L.; Zhang, J.; Zhao, L.; Gao, Q. Association between genetic variations in MTNR1A and MTNR1B genes and gestational diabetes mellitus in Han Chinese women. Gynecol. Obstet. Invest. 2013, 76, 221-227. [CrossRef] [PubMed] 
36. Hu, C.; Zhang, R.; Wang, C.; Yu, W.; Lu, J.; Ma, X.; Wang, J.; Jiang, F.; Tang, S.; Bao, Y.; et al. Effects of GCK, GCKR, G6PC2 and MTNR1B variants on glucose metabolism and insulin secretion. PLoS ONE 2010, 5, e11761. [CrossRef] [PubMed]

37. Chen, J.; Zheng, H.; Bei, J.X.; Sun, L.; Jia, W.H.; Li, T.; Zhang, F.; Seielstad, M.; Zeng, Y.X.; Zhang, X.; et al. Genetic structure of the Han Chinese population revealed by genome-wide SNP variation. Am. J. Hum. Genet. 2009, 85, 775-785. [CrossRef] [PubMed]

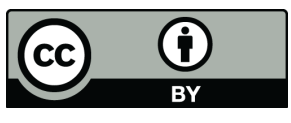

(C) 2016 by the authors; licensee MDPI, Basel, Switzerland. This article is an open access article distributed under the terms and conditions of the Creative Commons by Attribution (CC-BY) license (http://creativecommons.org/licenses/by/4.0/). 